\title{
CILIATED EPITHELIUM IN THE UTERINE CERVIX OF THE MACAQUE AND RABBIT
}

\author{
E. S. E. HAFEZ AND H. KANAGAWA \\ Departments of Gynecology-Obstetrics and Physiology, \\ Wayne State University School of Medicine, Detroit, Michigan, U.S.A.
}

(Received 8th June 1971, accepted 19th August 1971)

\begin{abstract}
Summary. Different types of secretory cells were observed in the cervical mucosa of the uteri of macaques and rabbits. The percentage of ciliated cells in the macaque $(10 \%)$ and rabbit $(62 \%)$ varies in different regions of the cervix. Kinocilia, observed in vitro, beat towards the vagina. The beating of cervical cilia does not seem to be of importance for the transport of spermatozoa to the uterine cavity. Scanning electron microscope studies indicate that kinocilia may be of functional significance for the release into the cervical lumen of material from the surface of adjacent secretory cells in the cervical crypts.
\end{abstract}

In the female reproductive tract, kinocilia play an important rôle in the transport of particles and directing the flow of luminal fluids. The directional beat of the fimbrial cilia propels fluid currents toward the oviducal ostium, and holds the egg cumulus and matrix on the surface of the fimbriae (Blandau, 1969). Although basic cilia structure and its variations throughout the biological systems are well documented (Fawcett, 1961 ; Satir, 1965), little is known about the mechanisms of ciliary motion.

The purpose of this experiment was to correlate observations in vitro and in vivo of the ciliated epithelium in the uterine cervix of the monkey and rabbit.

Fresh specimens of cervical mucosa, oviducal fimbriae and trachea were obtained from four crab-eating macaques, Macaca fascicularis, four stump-tail macaques, $M$. arctoides, and ten domestic rabbits before and after copulation. Longitudinal strips from epithelial layers were placed on glass slides containing one drop of warm culture medium H-597 (including 20\% inactivated calf serum and $2 \%$ sodium bicarbonate), and the coverslips were sealed to prevent evaporation. Cinemicrophotographs of the beating cilia were taken by phase contrast or interference microscopy at 24 frames/min, using Ektachrome $16 \mathrm{~mm}$ colour film with $\times 40$ or $\times 100$ objective and a $\times 10$ eyepiece (PI. 1, Figs. 1, 2 and 3).

Histological sections were stained with $\mathrm{H}$. and E., Mallory azan, Trichrome stain and with periodic acid Schiff's stain and Alcian blue for differential staining of ciliated and secretory cells. Segments of tissue were pinned to Dow Corning 780 building sealant, fixed in $6.5 \%$ cacodylate buffered glutaraldehyde, post-fixed for $1 \mathrm{hr}$ in buffered osmium fixative, and dehydrated in ethanol series. The tissue was then treated in freshly prepared Maraglass mixture 
(Maraglass 655, Cardolite NC 513, dibutyl phthalate BDMA), washed in hot acetone, polymerized overnight, first at $37^{\circ} \mathrm{C}$ then at $60^{\circ} \mathrm{C}$, and glued to scanning electron microscope stubs. After coating rotationally with gold-palladium metal, observations were carried out with a Cambridge scanning electron microscope.

The epithelial lining of the uterine cervix varied with the species, stage of reproductive cycle and interval from copulation. Different magnifications revealed interesting features of the cervical folds and openings of cervical crypts (Pl. 1, Figs. 4, 5 and 6).

Ciliated cells were found singly, or in groups. They contained few cytoplasmic granules, and well developed kinocilia. The percentage of ciliated cells in the cervical epithelium varied from 3 to $18 \%$ in the macaques and 46 to $90 \%$ in the rabbit (Table 1). Sections of the cervix uteri of the rabbit and macaque stained with the Mallory azan stain showed the best differentiation between the randomly distributed ciliated and secretory cells.

\section{TABLE 1}

FREQUENGY OF GILIATED GELLS IN THE GERVICAL EPITHELIUM OF FEMALE MACAQUE AND RABBIT

\begin{tabular}{l|c|c|c}
\hline \multirow{2}{*}{ Species } & \multicolumn{3}{|c}{$\%$ of cervical ciliated cells } \\
\cline { 2 - 4 } & External os & Mid cervix & Internal os \\
\hline Stump-tail macaque, $M$. arctoides & 3 & 11 & 8 \\
Crab-eating macaque, $M$. fascicularis & 4 & 18 & 18 \\
Domestic rabbit & 46 & 48 & 90 \\
\hline
\end{tabular}

The cilia in the cervix of the macaque stained either blue or red. Whether these colours indicate two types of ciliated cells or different stages of one cell type is not known. The cilia and their basal bodies were PAS-reactive and stained with Alcian blue for acid mucopolysaccharides. Glycogen has been found in the basal bodies of the oviducal cilia (Fredricsson \& Björkman, 1962). The staining reaction of cervical epithelium should be evaluated with care due to the adhesion of secretory products from the adjacent secretory cells.

As soon as the cervix was opened, a piece of longitudinal surface tissue was removed with scissors and transferred to a glass slide in a drop of culture medium. The epithelial cilia of the fimbriae, oviduct and cervix, as observed in vitro, beat towards the vagina, and their pattern of beat was similar to those organs as well as in the trachea. Two types of ciliary motility were recognized: an effective stroke and a recovery stroke (Text-fig. 1). In the effective stroke, the cilia sweep rapidly in a stiff and slightly wavy motion. In the recovery stroke, the cilia bend near the basal body and the degree of bending proceeds as a slow wave toward the tip. The recovery stroke carries the cilia back to the effective stroke position.

Segments of cervical epithelium collected $1 \mathrm{hr}$ after natural copulation were observed in vitro. Most of the motile spermatozoa in the middle of the lumen were swimming against the effective stroke of cilia beat. Some of the inactive sperm 


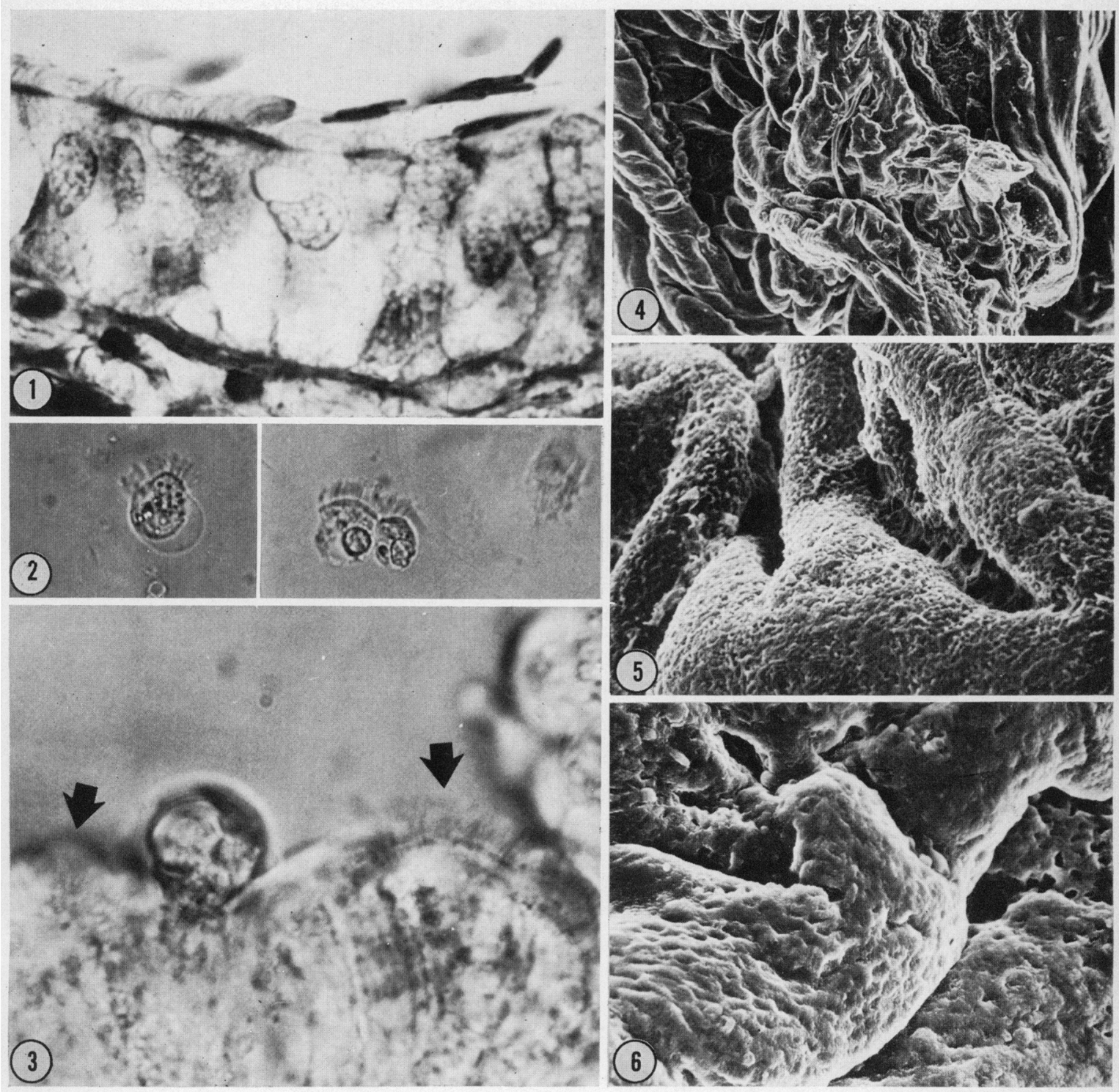

lins. 1 to 3. Micrographs of uterine cervical cells. Figure 1 was taken with a Nomarski interference microscope and Figs. 2 and 3 with a \%eiss phase contrast microscope.

Fic. 1. Histological section of the rabbit cervix, $1 \mathrm{hr}$ after copulation, showing spermatozoa in the lumen. H. and E. $\times 6.50$.

Fic. 2. Individual ciliated cells from the cervix of a crab-eating macaque were still beating after 2 days in tissuc: culture. $\times 650$.

lig. 3. Ciliated cells from the cervix of a rabbit maintained their beating for 17 days when cultured in zitro. Arrows show movement of cilia. $\times 6.50$.

Fics, 4 to 6. Scanning electronmicrographs of the epithelial lining of the uterine cervix of the rabbit. Sections fixed in glutaraldehyde, embedded in Maraglas with partial polymerization before scasoning of the plastic. Note the complexity of the cervical folds and crypts of different sizes. Fig. 4, $\times 38$; Fig. $5, \times 140$; Fig. $6, \times 380$.

(Facing p. 92) 
heads were attached to the ciliary tips or seen among the cilia. Agglutinated sperm heads were often found attached to cilia.

The direction of cervical ciliary beat, appeared to present an insurmountable obstacle for the movement of the spermatozoa from the cervix to the uterine cavity. In the presence of massive numbers of spermatozoa following copulation, however, the directional beating of the cilia does not inhibit sperm transport. It would appear that the cervical cilia are of importance for the directional flow of the cervical mucus from the narrow crypts to the cervical lumen. Preliminary observations on the distribution pattern of ciliated and secretory cells, as observed by scanning electron microscopy, indicate that the cilia may facilitate the release of secretory granules adhering to the surface of adjacent secretory cells. It is not known whether the cervix uteri in mammals acts as a
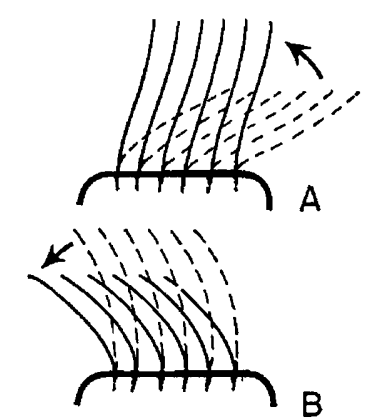

$A$

$B$

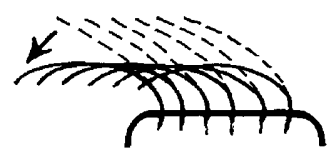

C

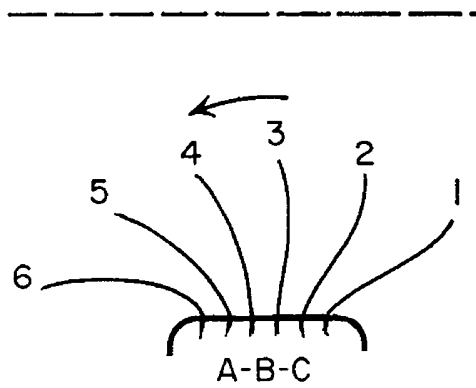

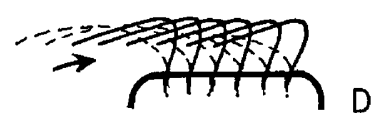
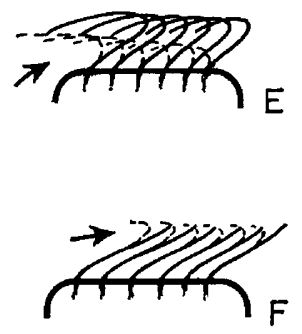

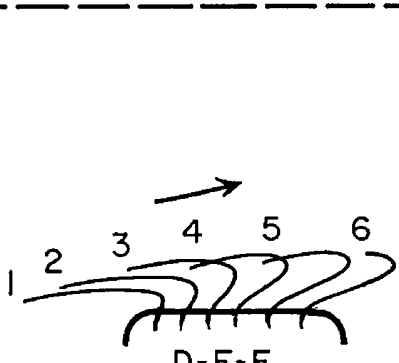

Text-FIG. 1. Two types of ciliary beat: serial effective strokes from $A$ to $C$, and recovery strokes from $\mathrm{D}$ to $\mathrm{F}$.

'sperm reservoir', a 'sperm barrier' to prevent massive numbers of spermatozoa from reaching the site of fertilization, or a 'sperm selector' to hinder the transport of abnormal and inactive spermatozoa to the uterine cavity. It is possible that the physiological mechanisms of sperm transport, the functions of cervical mucus and cervical cilia and the interactions between spermatozoa, cervical mucus, cervical epithelium and leucocytes vary between mammalian species. Since the investigations of Parker $(1930,1931)$ on the rôle of cilia in sperm 
transport in the rabbit, pigeon and tortoise, no similar research has been conducted in other species.

The height and number of ciliated cells seem to vary with the reproductive state of the female. In the rhesus monkey, the ciliated epithelium of the ampullary and fimbriated portions of the oviduct is sensitive to varying levels of oestrogen and progesterone during the menstrual cycle (Brenner, 1969). Stroboscopic observations of oviducal ciliated cells have shown that cilia beat approximately 1200 times/min (Borell, Nilsson \& Westman, 1957). Progesterone increases the rate of beat by $20 \%$. Cilia of different regions seem to vary in their sensitivity to changes in oestrogen-progesterone blood levels, the cilia of the fimbriae being more responsive than the cervical cilia (unpublished data). Further studies are being carried out on endocrine control of the ciliogenic cycle of the cervical epithelium in vitro and in vivo.

The authors wish to express their appreciation to Dr St. Jaszczak, and Dr M. Nawar, for assistance. This project was supported in part by Ford Foundation Grant No. 710-0287, and the Research and Education Fund of Hutzel Hospital. Thanks are also due to Professor T. N. Evans for criticism and financial support.

\section{REFERENCES}

Blandau, R. J. (1969) Gamete transport-comparative aspects. In: The Mammalian Oviduct. Eds. E. S. E. Hafez and R. J. Blandau. University of Chicago Press.

Borell, U., Nilsson, O. \& Westman, A. (1957) Ciliary activity in the rabbit Fallopian tubes during oestrus and after copulation. Acta obstet. gynec. scand. 36, 22.

BRENNER, R. M. (1969). The biology of oviductal cilia. In: The Mammalian Oviduct. Eds. E. S. E. Hafez and R. J. Blandau. University of Chicago Press.

FAwcETT, D. W. (1961) Cilia and flagella. In: The Cell, Vol. II, Eds. J. Brachet and A. E. Mirsky. Academic Press, New York.

Fredricsson, B. \& BJörKMAN, N. (1962) Studies on the ultrastructure of the human oviduct epithelium in different functions states. Z. Zellforsch. mikrosk. Anat. 58, 387.

Parker, G. H. (1930) The passage of spermatozoa and ova through the oviducts of the rabbit. Proc. Soc. exp. Biol. Med. 27, 826.

Parker, G. H. (1931) The passage of sperms and eggs through the oviducts in terrestial vertebrates. Phil. Trans. R. Soc. 219, 381.

SATIR, P. (1965) Structure and function in cilia and fagella: protoplasmatologia. In: Handbuch der Protoplasmaforchung, Vol. 3/E. Springer, New York. 